\title{
The Relationship Between Service Quality Antenatal Care and Low Birth Weight in Indonesia: IDHS in 2017
}

\author{
Aryandi Darwis $^{1 *}$, Asnawi Abdullah ${ }^{1}$, Maidar ${ }^{1}$, Aulina Adamy ${ }^{1}$, Riza Septiani², \\ Nurjannah $^{3}$
}

\author{
${ }^{1}$ Postgraduate Program of Public Health, University Muhammadiyah Aceh, Banda Aceh, Indonesia \\ ${ }^{2}$ Faculty of Public Health, University Muhammadiyah Aceh, Banda Aceh, Indonesia \\ ${ }^{3}$ Faculty of Medicine, University Syiah Kuala, Banda Aceh, Indonesia \\ *Corresponding Author. Email: Aryandi.darwis@gmail.com
}

\begin{abstract}
Based on IDHS (Indonesian Demographics Health Survey) data in 2017, the antenatal care (ANC) services provided by competent healthworkers is $97.5 \%$ in the first visit (K1) and $77.4 \%$ in fourth visit (K4). Meanwhile, based on Growth Chart record, it is found that Low Birth Weight (LBW) cases is still high (7.1\%). This research aimed to determine the quality of service of ANC in Primary Health Care (PHC) and Hospitals and to analyse the factors related to LBW. This research was conducted using secondary data from IDHS in 2017 with cross-sectional design. The number of samples in this study is 16,342 and data were analysed using logistics regression. The results of the study shows that the proportion of ANC access in PHC is $93.38 \%$, with no significant differences compared to hospitals (93.40\%). Univariate analysis shows the percentage of LBW is $7.14 \%$ and the proportion of respondents accessing low quality of ANC services is $93.27 \%$. Bivariate analysis shows there is a relationship between quality of ANC service and LBW ( $\mathrm{P}$ value: 0.003). Multivariate analysis shows that the respondents who experienced low quality of ANC have a risk of experiencing deliveries with LBW of 1.56 times compared to good quality of $\mathrm{ANC}(\mathrm{OR}=1.56 ; 95 \% \mathrm{CI}=1.05-2.39)$ and $(\mathrm{AOR}=1.71 ; 95 \%$ $\mathrm{CI}=1.21-2.41)$. LBW could result in neonatal death, asphyxia and other complications. In order to reduce these problems and complications, pregnant women should avoid risk factors of LBW and accessing adequate and qualified ANC. It is suggested for the Midwives to provide appropriate health monitoring for pregnant women. Also, health facilities should be provided to accommodate ANC services in order to maintain healthy condition for babies and mothers throughout the pregnancy.
\end{abstract}

Keywords: antenatal care, IDHS 2017, LBW, quality services.

\section{INTRODUCTION}

According to the World Health Organization (WHO) 2015, Infant Mortality Rate (IMR) in the world in 2012 amounted to 39 deaths per 1,000 live births, which is high. IMR is high especially in developing countries. Indonesia as a developing country has a IMR that is almost close to the world's AKB [1]. Based on the results of the Indonesian Demographic and Health Survey (IDHS) 2012, there were 32 infant deaths from 1,000 live births and this figure is still far from the Sustainable Development Goals target that must be achieved in 2030 which is 12 deaths from 1,000 live births [2].

Then in the IDHS (2017), infant mortality to 24 deaths per 1,000 live births in the period 2013-2017 there was a decrease from the previous survey [3]. The majority of infant deaths in 2017 occur in the perinatal period (0-7 days). According to the Ministry of Health (2014) and IDHS (2017), the prevalence of neonatal death in perinatal period that caused by Intra-Uterine Fetal Death (IUFD) is $29.5 \%$ and Low Birth Weight (LBW) is $7.1 \%[3,4]$.
The results of the Indonesian Demographic and Health Survey (IDHS, 2017) show a decrease in IMR in Indonesia, in the 2002-03 IDHS is 35 per 1000 live births, then the 2007 IDHS is 34 per 1000 live births, then the 2012 IDHS is 32 per 1000 births and the last 2017 IDHS is 24 per 1000 live births ${ }^{3}$. However, this figure is still higher when compared to other Southeast Asian countries in 2002, namely Malaysia at 8 per 1000 live births, Brunei Darussalam 6 per 1000 live births and Singapore 3 per 1000 live births [5].

The main problem faced by babies with LBW is the inability to adapt to the surrounding temperature, which often results in death of the baby. Premature baby's organs are not functioning properly, intensive care can help babies overcome obstacles or difficulties in efforts to adjust to extrauterine life, so services during pregnancy also need to be considered properly by completing pregnancy check-ups can reduce LBW rates [6].

Antenatal Care (ANC) is a routine health screening service for pregnant women to diagnose obstetric complications as well as to provide information about 
lifestyle, pregnancy and childbirth [7]. Every pregnant woman is highly recommended to conduct a comprehensive quality ANC examination at least 4 times, namely at least 1 time in the first trimester (before 14 weeks gestation), at least 1 time in the second trimester (14-28 weeks gestational age) and at least 2 times in the trimester third (28-36 weeks and after 36 weeks of gestation) includes at least 1 visit between the husband or family member. The first ANC visit is highly recommended at 8-12 weeks gestation [7,8]. In 2015, almost all pregnant women $(95.75 \%)$ in Indonesia had their first pregnancy checkup (K1) and $87.48 \%$ of pregnant women had a complete pregnancy check up with a frequency of at least 4 times according to these provisions (K4) [9].

\section{METHOD}

This study is an analysis of secondary data IDHS 2017 using cross-sectional design with a quantitative approach. Cross-sectional is an epidemiological study design that studies the relationship of disease and exposure (research factors) by observing the status of exposure and disease simultaneously in individuals from a single population, at one time or period [10,11].

The samples in this study were all IDHS 2017 samples accounted for 16.343 women aged $>15-49$ years, currently or had experience of marriage and gave birth with live births in the last 5 (five) years before the survey conducted. The inclusion criteria were single birth, baby was weighed at birth, and performed the last antenatal examination at gestational age $>9$ months, while the exclusion criteria were documented data that was not available in full accordance with the research variables [3].

Research locations includes all provinces in Indonesia, conducted between 24 July and 30 September 2017. The secondary data was analyzed by researchers with several different variables in 2019 and Data were analysed using logistics regression with Stata 12.0 for univariate, bivariate and multivariate analysis. Overall, ANC service quality was measured by its utilization based on several items of services (such as: K1-K4 visits comprised into 10T services namely Body Weight, Body Height, Urine Test, Blood Test, Vaccine, Arm Circumference, Fundal Height, Fe administration, Fetal Heart Beat, Consultation) and this variable is used for multivariate analysis (with adjusted SES) in investigating its relationship with LBW cases. The adjustment of SES considering several variables including health services for ANC, remoteness, maternal age, maternal education, parity, deliveries interval, smoking status.

\section{RESULTS AND DISCUSSION}

Table 1. Frequency Distribution of ANC in Indonesia

\begin{tabular}{llcc}
\hline \multicolumn{1}{c}{ Health Services for ANC } & n & $\mathbf{\%}$ \\
\hline 1 & Hospital & 763 & 4.66 \\
\hline 2 & Primary Health Care (Puskesmas) & 631 & 3.86 \\
\hline 3 & $\begin{array}{l}\text { Respondent's Home, Village Health } \\
\text { Posts (Pokesdes), Private Clinics, Private } \\
\text { Practice }\end{array}$ & 14.949 & 91.47 \\
\hline \multicolumn{1}{c}{ Total } & $\mathbf{1 6 . 3 4 3}$ & $\mathbf{1 0 0}$ \\
\hline
\end{tabular}

Table 1 shows that pregnant mothers who had ANC visit throughout their pregnancy in the hospital $(4.66 \%)$ are a little bit higher than the Primary
LBW can increase morbidity and mortality in newborns, such as complications of asphyxia, hypothermia, sepsis, and so on. From the IDHS data (2017), it was found that the coverage of antenatal services (once received antenatal services) examined by competent health workers (K1) was quite high at $97.5 \%$ and ANC (K4) service at $77.4 \%$ was expected to reduce the number LBW, but it turns out the LBW figure is still quite high at $7.1 \%$ based on the note on the Growth Chart Record (KMS) or mother's report. Seeing the still high LBW rate $(7.1 \%)$ it is necessary to question antenatal care services. Thus, the problem raised in this study is that the relationship between antenatal care (10T) services to LBW events is not yet known [3].

Health Care $(3.86 \%)$. Yet, this percentage still considered low compared to other lower level health services.

Table 2. Frequency Distribution of LBW in Indonesia

\begin{tabular}{llcc}
\hline & Low Birth Weight & n & \% \\
\hline $1 \quad$ No $(\geq 2500$ Gram $)$ & 15.097 & 92.86 \\
\hline $2 \quad$ Yes $(<2500$ Gram $)$ & 1.246 & 7.14 \\
\hline Total & $\mathbf{1 6 . 3 4 3}$ & $\mathbf{1 0 0}$ \\
\hline
\end{tabular}

Table 2 shows that the proportion of LBW cases in Indonesia was $7.14 \%$.

Table 3. Frequency Distribution of the Quality of Antenatal Care Services in Indonesia

\begin{tabular}{llcc}
\hline & Quality Antenatal Care Service & $\mathbf{n}$ & $\mathbf{\%}$ \\
\hline 1 & Adequate & 1.069 & 6,73 \\
\hline 2 & Inadequate & 15.274 & 93,27 \\
\hline Total & $\mathbf{1 6 . 3 4 3}$ & $\mathbf{1 0 0}$ \\
\hline
\end{tabular}

Table 3 shows that majority of quality of ANC services in Indonesia are inadequate $(93.27 \%)$ compared to adequate category $(6.73 \%)$.

Table 4. Bivariate Analysis The sites of ANC Services with Quality of ANC Services in Indonesia

\begin{tabular}{|c|c|c|c|c|}
\hline \multirow[b]{2}{*}{ No } & \multirow{2}{*}{ ANC Services } & \multicolumn{2}{|c|}{ Quality of Antenatal Care Service } & \multirow[b]{2}{*}{ Total (\%) } \\
\hline & & Adequate (\%) & Inadequate (\%) & \\
\hline 1 & Hospital & $49(6,60)$ & $714(93,40)$ & $763(100)$ \\
\hline 2 & $\begin{array}{l}\text { Primary Health Care } \\
\text { (Puskesmas) }\end{array}$ & $45(6,62)$ & $586(93,38)$ & $631(100)$ \\
\hline 3 & $\begin{array}{ll}\text { Respondent's } & \text { Home, } \\
\text { Village Health Posts } \\
\text { (Poskesdes), } & \text { Privare } \\
\text { Clinics, } & \text { Private } \\
\text { Practice } & \end{array}$ & $972(6,64)$ & $13.974(93,36)$ & $14.949(100)$ \\
\hline
\end{tabular}

Table 4 shows result of bivariate analysis, the proportion of respondents who experiencing inadequate quality of ANC service in the Hospital is 93.40\% and similarly in Health Center (93.36\%).

Table 5. Bivariate Analysis Quality of ANC Services with LBW Events in Indonesia

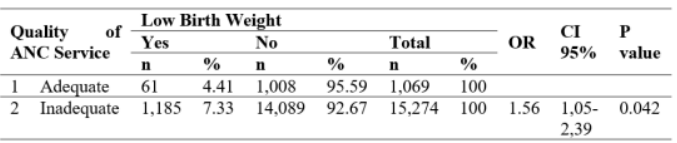

Based on Table 5 the bivariate analysis describes that the percentage of $\mathrm{LBW}$ in inadequate $\mathrm{ANC}$ services is $7.33 \%$ and the proportion of LBW is 
lower in adequate ANC services for $4.41 \%$. Statistical tests show that there is a relationship between the quality of antenatal care services with LBW events ( $\mathrm{p}$ value 0.042 and $\mathrm{OR}=1.56$ ), meaning that inadequate quality of ANC services give rise to a risk of experiencing LBW by 1.56 times compared to the adequate quality of antenatal care services.

Table 6. Multivariate Analysis: Quality of antenatal care services and LBW in Indonesia

\begin{tabular}{|c|c|c|c|c|c|c|c|}
\hline \multirow{3}{*}{\multicolumn{2}{|c|}{$\begin{array}{l}\text { Quality of Antenatal } \\
\text { Care Service }\end{array}$}} & \multicolumn{6}{|c|}{ Low Birth Weight } \\
\hline & & \multicolumn{3}{|c|}{ Unadjusted SES } & \multicolumn{3}{|c|}{ Adjusted SES } \\
\hline & & OR & $\begin{array}{l}\text { CI } \\
95 \% \\
\end{array}$ & P Value & OR & $\begin{array}{l}\text { CI } \\
95 \% \\
\end{array}$ & P Value \\
\hline 1 & Adequate & & & & & & \\
\hline 2 & Inadequate & 1.56 & $\begin{array}{l}1,05- \\
2,39\end{array}$ & 0.042 & 1.71 & $\begin{array}{l}1,21- \\
2,41\end{array}$ & 0.001 \\
\hline
\end{tabular}

Multivariate analysis describes that respondents with inadequate quality of ANC services had a risk of giving birth to LBW 1.56 times and 1.71 times or almost 2 times compared to adequate quality antenatal care services with $(\mathrm{OR}=1.56 ; 95 \% \mathrm{CI}=$ $1.05-2.39)$ and $(\mathrm{AOR}=1.71 ; 95 \% \mathrm{CI}=1.21-2.41)$.

In this study the quality of ANC is said to be inadequate if pregnant women does not receive all ANC services including: K1-K4 visits, at least 1 time visit in the first trimester, and 1 time in second trimester and 2 times in the third trimester, and also received a minimum standard of "10T" services and notified for any signs of pregnancy complications. Multivariate analysis describes that respondents with inadequate quality of ANC services had a risk of giving birth to LBW for 1.56 times or almost 2 times compared to adequate quality of ANC services $(\mathrm{OR}=1.56 ; 95 \% \mathrm{CI}=1.05-2.39)$ and $(\mathrm{AOR}=1.71$; $95 \% \mathrm{CI}=1.21-2.41)$.

Several previous studies shows in line findings with this study although the operational definitions of variables and other aspects of antenatal care are not exactly similar with this study. Research Simarmata (2010) with 2007 IDHS data sources on bivariate analysis showed a significant relationship with a pvalue of 0,0001 [12]. Then a similar study was also conducted by Atriyanto (2006) with the 2002-2003 IDHS data source but the study design was different from this study, obtained an $\mathrm{OR}=2.71$ meaning that mothers who received poor or incomplete antenatal quality were likely to be at risk 2.71 times greater birth weight LBW than mothers with good antenatal quality [13].

Then according to Winkjosastro (2006) antenatal aims to detect abnormalities that may be present or will arise in the pregnancy are quickly identified, and can be resolved immediately before the adverse effect on the pregnancy by conducting antenatal care checks. Then if a pregnant woman does not do a pregnancy check, it will not be known whether the pregnancy is going well or experiencing a high risk condition and obstetric complications that can endanger the lives of the mother and fetus because it can cause high morbidity and mortality [14].
Furthermore, in the study of Khanal et al. (2014) in NDHS (Nepal Demographic Health Survey) or suggested that conducting routine antenatal care can reduce the risk of LBW according to survey data collected in 2006 and 2011 [15]. Then if not attending antenatal care increases the likelihood of having LBW infants more than twice ( $\mathrm{OR}=2,301)$. In research conducted by da Fonseca et al. (2014) in Brazil revealed that $\mathrm{LBW}$ is associated with ANC visits adjusted to gestational age having more than one time $(\mathrm{OR}=1.78)$, then regardless of the relationship found in research in Brazil, they cannot conclude that LBW is only can be prevented with adequate ANC components, because LBW also has a relationship with other risk factors [16].

In the results of the study the percentage of LBW by $7.14 \%$, LBW events have a negative impact because it will result in neonatal death, then such as asphyxia and other events are also very vulnerable to occur if the baby is born with LBW. Furthermore, with the logistic regression test the quality of antenatal care services has an influence on LBW, poor quality of antenatal care services has a risk of LBW almost 2 times greater than the quality of poor antenatal care with $(\mathrm{OR}=1.56 ; 95 \% \mathrm{CI}=1.05-2.39)$ and $(\mathrm{AOR}=$ $1.71 ; 95 \% \mathrm{CI}=1.21-2.41)$. For health workers, especially midwives in Indonesia, to be able to invite pregnant women to increase antenatal care visits, this aims to avoid risk factors for LBW in health centers or in hospitals. Midwives in the village always monitor the health of pregnant women and are properly recorded so that they become a reference for making decisions and giving appropriate advice to pregnant women.

Improve $\mathrm{MCH}$ management, such as the distribution of equipment needed for self-help antenatal services or assistance such as iron tablets, Growth chart record for pregnant women, body scales for mothers and babies, and counseling tools. Also, by conducting good quality of ANC, pregnant mothers will have more time to discuss on dietary and nutritional intake that support the improvement of baby weight during pregnancy.

\section{ACKNOWLEDGMENT}

Thank you to the IDHS (Indonesian Demographic Health Survey) for organizing information on maternal and child health. Then the IDHS has facilitated the survey data so that it can be accessed $^{2,3}$.

\section{REFERENCES}

[1] WHO. Global status report on road safety 2015: World Health Organization; 2015.

[2] IDHS, Indonesian Demographic and Health Survey (SDKI) 2012, Jakarta: BKKBN, 2012.

[3] IDHS. Indonesian Demographic and Health Survey: BKKBN, BPS; 2017. 
[12] Simarmata O.S., Antenatal Service Quality Relationship to the Occurrence of Low Birth Weight Babies: University of Indonesia; 2010.

[5] Ministry of Health of the Republic of Indonesia., Essential Neonatal Health Services: Jakarta: Ministry of Health; 2005

[6] Hariati S., Effectiveness of music therapy on increasing body weight and body temperature of premature babies in Makassar: Dissertation. Postgraduate Program: Depok; 2010.

[7] Ariyanti D.F., Analysis of the quality of antenatal services by midwives at the Puskesmas in Purbalingga Regency: University of Diponegoro; 2010.

[8] The Indonesian Ministry of Health, Catalog In Issue. RI Ministry of Health, 2013.

[9] Minister of Health of the Republic of Indonesia, Regulation of the Minister of Health of the Republic of Indonesia Number 43 of 2016 concerning Minimum Service Standards in the Field of Health, Jakarta: Minister of Health RI, 2016.

[10] Notoatmodjo S., Health research methodology: Jakarta: creative design; 2010.

[11] Wibowo A., Practical research methodology in health, Jakarta: Rajawali Press; 2014.

[13] Atriyanto P., Effect of quality of anternatal care (based on service frequency, service schedule, and counseling) on the incidence of low birth weight babies (LBW) in Indonesia: Analysis of the 2002-2003 IDHS data: Universitas Indonesia. Faculty of Public Health; 2006.

[14] Wiknjosastro H., Midwifery Science, Jakarta: Yayasan Bina Pustaka Sarwono Prawiroharjo 2006.

[15] Khanal V., Zhao Y. \& Sauer K., Role of antenatal care and iron supplementation during pregnancy in preventing low birth weight in Nepal: comparison of national surveys 2006 and 2011, Arch Public Health, 2014; 72 (1): 4

[16] da Fonseca C.R., Strufaldi M.W., de Carvalho L.R. \& Puccini R.F., Adequacy of antenatal care and its relationship with low birth weight in Botucatu, Sao Paulo, Brazil: a case-control study, BMC Pregnancy Childbirth, 2014; 14: 255. 